\title{
RESENHA BIBLIOGRÁFICA
}

\section{Marco Flávio da Cunha Resende}

Abingdon: Routledge, 2011

Entre as décadas de 1990 e 2000 observou-se uma sequência de crises financeiras e cambiais em países que promoveram a abertura financeira de suas economias. A crise iniciada nos Estados Unidos em 2008 foi a principal delas, dada sua escala global e profundidade. Deste modo, o tema da liberalização financeira voltou à tona no debate político e acadêmico, provocando mudanças de opinião em setores da sociedade e em instituições multilaterais, como o FMI, que até pouco tempo atrás tinha esta questão como resolvida: era radicalmente contra os controles de capitais.

Dado o quadro de crise da economia mundial, chega em momento oportuno o livro Financial Liberalization and Economic Performance: Brazil at the Crossroads, de Luiz Fernando de Paula, publicado pela Routledge, 2011, com prefácio de Jan Kregel e citações deste e de Philip Arestis. O livro aponta e analisa os determinantes, impactos e características da liberalização financeira no Brasil, considerando suas duas dimensões: i) abertura da conta Capital e Financeira do Balanço de Pagamentos e ii) penetração de bancos estrangeiros no setor bancário doméstico do país. Trata-se de livro cujo tema é de extrema relevância e atual.

Ao contemplar estas duas dimensões o livro tem o mérito de abordar o tema da liberalização financeira no Brasil de modo completo, além de realizar análise abrangente e profunda do processo de abertura financeira iniciado no Brasil 20 anos atrás. O livro combina análise teórica e empírica de forma equilibrada, além de considerar diversos aspectos da liberalização financeira no Brasil que conferem um

- Professor do Departmento de Economia da Univerisdade Federal de Minas Gerais (UFMG) Vice-president Associação Keynesiana Brasileira (AKB) - Endereço para contato: Av. Antônio Carlos, 6.627, sala 3049 - Belo Horizonte, MG - CEP: 31270-901 E-mail: resende@cedeplar.ufmg.br 
caráter de completude a esta obra de Paula. São aspectos tais como aqueles relacionados à legislação, à conjuntura nacional e internacional, requeridos para a compreensão do contexto em que a abertura foi promovida, à evolução histórica dos modelos macroeconômicos adotados no país, às políticas econômicas adotadas, bem como suas causas e consequências, entre outros.

O livro está dividido em três partes. A primeira parte avalia de modo teórico e empírico a relação entre liberalização financeira, crescimento econômico e estabilidade macroeconômica no Brasil. A segunda parte foca a entrada de bancos estrangeiros no país, avaliando as peculiaridades do caso brasileiro e a relação benefícios esperados/ benefícios alcançados. A terceira parte do livro remete o leitor ao sumário e conclusões.

Na primeira parte do livro, o capítulo 2 analisa os custos e benefícios da Liberalização Financeira (LF), em particular para os países em desenvolvimento. Focam-se as abordagens Convencionais, Novo Keynesiana e Pós-Keynesiana presentes na literatura. O autor sintetiza com precisão os argumentos favoráveis à LF, e, ainda, explica os vários canais através dos quais se dariam os benefícios potencias da LF para países emergentes. Com a mesma clareza e objetividade são sintetizados os argumentos de cunho Keynesiano dos críticos da LF. Em seguida, há excelente síntese de ampla gama de trabalhos empíricos sobre o tema da LF. Conclui-se que não há uma relação de causalidade robusta entre LF e crescimento econômico, além de haver indícios de que a liberalização da conta de capitais provoca instabilidade macroeconômica.

O capítulo 3 analisa a evolução da economia brasileira e da política econômica entre 1990-2009, no contexto da abertura da economia e de elevada mobilidade de capitais. É oferecida ao leitor a análise detalhada da macroeconomia brasileira e de seus problemas naquele período, como também da política econômica adotada e seus resultados.

O capítulo conta com dados e evidências empíricas que facilitam a leitura e o acompanhamento dos argumentos elaborados pelo autor. Destacam-se três pontos: i) análise sobre a transição que a economia brasileira faz do modelo nacional-desenvolvimentista para o modelo liberal inspirado no Consenso de Washington, a partir de 
1990, até alcançar, após a crise cambial de 1999, o Novo Consenso Macroeconômico - este é baseado no tripé formado por metas de inflação, taxa de câmbio flutuante e superávit fiscal público, no contexto de conversibilidade da conta de capitais; ii) mudança no regime de política econômica no governo Lula, que reduziu a vulnerabilidade externa da economia permitindo, pela primeira vez em muitas décadas, que os choques externos produzissem não mais do que curto espasmo no crescimento econômico; e, iii) detalhada análise das medidas de política econômica adotadas no Brasil no âmbito da crise financeira mundial de 2008 e os resultados obtidos.

A liberalização dos fluxos de capitais no Brasil nos anos 1990 deu-se de modo gradual e contínuo, sem grandes modificações na legislação. Não obstante, o capítulo 4 contém relevantes detalhes deste processo, como é o caso do redesenho das contas CC5, em 1992, que representou a introdução de facto da conversibilidade da conta capital e financeira do balanço de pagamentos do Brasil.

O capítulo 4 examina a evolução da legislação sobre fluxos de capitais no Brasil, enfatizando o contexto a partir do qual a LF no país deve ser entendida: trata-se de decisão de política de promover a LF no âmbito das reformas liberais implementadas com base no Consenso de Washington. O capítulo apresenta dois períodos principais: no primeiro, anos 1990, analisa-se o processo de LF; no segundo período estão detalhadas as medidas de consolidação e simplificação da legislação sobre fluxos de capitais, na década de 2000.

Para explicar o processo de LF nos anos 1990 é apresentado ao leitor o arcabouço legal sobre o mercado cambial e o sistema financeiro, cuja montagem teve início na década de 1930. O capítulo mostra a trajetória de construção da estrutura legal e o modus operandi dos mercados cambial e monetário no Brasil entre 1930 e 1990. Mostra, também, a conjuntura internacional e as mudanças na legislação brasileira que introduziram a LF no país no final da década de 1980. Esta tarefa é feita de modo sintético e objetivo. Em seguida são apontados o processo de desregulamentação financeira e suas mudanças legais nos anos 1990, e as medidas de consolidação e simplificação da legislação relativa à LF, nos anos 2000.

O capítulo 5 é estimulante por apresentar o debate iniciado por Pérsio Arida (ex-presidente do Banco Central do Brasil) e Edmar 
Bacha (ex-presidente do BNDES), em 2002, relativo aos efeitos da LF na economia brasileira. Arida e Bacha argumentaram que a consolidação da estabilidade macroeconômica no país e a redução da sua taxa de juros básica exigiriam a plena conversibilidade da conta capital e financeira do balanço de pagamentos, pois esta fortaleceria o tripé de política econômica formado por: câmbio flutuante, metas de inflação e superávit público primário. Participaram do debate com críticas à proposta de plena conversibilidade do Real: Belluzzo, Carneiro, Oreiro, Paula, Ferrari-Filho, Jayme Jr., etc.

Na seção 5.3 os argumentos de Arida, favoráveis à plena conversibilidade do Real, são desmontados um a um. Paula demonstra com perspicácia e precisão contradições nos argumentos de Arida, e, ainda, aponta evidências empíricas que sugerem resultados opostos aos previstos por este. Entre as conclusões sobre o tema da conversibilidade plena do Real está a possibilidade de aumento da instabilidade macroeconômica.

O capítulo 6, último da primeira parte do livro, oferece uma avaliação empírica sobre a relação entre LF, desempenho econômico e estabilidade macroeconômica no Brasil. O capítulo é uma sequência natural do capítulo anterior, pois o exercício econométrico conduzido, usando a metodologia VAR (função impulso-resposta), visa: i) testar a hipótese de Arida de que a LF leva à redução do risco-país e à queda da taxa de juros doméstica; ii) testar a hipótese presente na literatura internacional de que a LF impacta positivamente o crescimento e a estabilidade macroeconômica, além de disciplinar a política econômica.

No estudo empírico para o período que se estende do segundo trimestre/1994 até o quarto trimestre/2007 foram estimados dois modelos: um deles contempla um índice de jure de controles de capitais e o outro um índice de facto. Os resultados encontrados não corroboram com a tese de Arida/Bacha e sugerem que a LF afeta negativamente o produto e a estabilidade macroeconômica no Brasil. Por fim, os resultados encontrados por Paula indicam que os fluxos de capitais no país dependem mais de outros determinantes, internos e externos, do que da LF, abrindo-se uma agenda de pesquisas futuras. 
O primeiro capítulo da segunda parte do livro, capítulo 7, analisa os determinantes, as características e a evolução da internacionalização bancária mundial. O capítulo inicia-se com análise das mudanças recentes na indústria bancária mundial e mostra que a desregulamentação financeira, a competição internacional, desenvolvimentos tecnológicos (tecnologia da informação e comunicações), etc., levaram à recente onda de reestruturação e aumento das fusões e aquisições (F\&A) na indústria bancária mundial.

Com o recrudescimento da competição o mercado bancário tornouse crescentemente contestável e a atividade tradicional dos bancos perdeu lucratividade, o que ensejou a diversificação de suas atividades e a busca por ganhos de escala. Bancos passaram, então, a expandir suas atividades para dentro e para fora das fronteiras nacionais, por meio de F\&A, entrando, inclusive, no mercado de varejo de economias emergentes nos anos 1990. O processo foi comandado, principalmente, por bancos europeus e gerou grandes conglomerados financeiros.

Paula realiza um desdobramento da teoria da internacionalização bancária ao demonstrar que o motivo para esta terceira onda de internacionalização dos bancos não foi o mesmo verificado nas ondas anteriores - o acompanhamento de clientes cujos negócios expandiram-se para outros países. Nesta terceira onda, fatores tais como desregulamentação financeira, recrudescimento da competição, oportunidades de lucro e menor eficiência de bancos em outros mercados, etc., levaram à internacionalização bancária. Como resultado, observou-se a internacionalização e a concentração bancária em âmbito mundial.

Ainda, o capítulo apresenta resultados de estudos empíricos, sugerindo que na atual onda de internacionalização os bancos estrangeiros são menos eficientes que os bancos domésticos em países desenvolvidos, mas mais eficientes que bancos domésticos em países em desenvolvimento. Ademais, a penetração de bancos estrangeiros elevou a eficiência dos bancos domésticos.

O capítulo 8 analisa os determinantes da expansão dos bancos estrangeiros na América Latina no âmbito da terceira onda de internacionalização bancária iniciada nos anos 1990. Bancos europeus, principalmente espanhóis, são os protagonistas deste processo. 
O capítulo analisa, também, os pontos em comum e as diferenças nas estratégias dos maiores bancos europeus na América Latina e no Brasil: Santander, BBVA, HSBC e ABN AMRO. Ademais, o capítulo está recheado de dados sobre concentração bancária no mundo e na região latino-americana, como também sobre a lucratividade e a participação recente de cada um destes bancos europeus nos principais mercados da América Latina.

O capítulo apresenta interessantes diferenças do processo de F\&A bancárias, verificadas em mercados maduros e das economias emergentes. Neste ponto o autor mostra a ponte entre esta segunda parte do livro e a primeira parte: a resposta às crises dada pelos governos das economias emergentes e encorajada pelas instituições financeiras internacionais, foi acelerar a LF e (re)capitalizar os bancos com a ajuda de investidores estrangeiros. Ou seja, as crises da segunda metade dos anos 1990 (crise do México, da Ásia, etc.) estimularam ainda mais a LF que, por sua vez, favoreceu a entrada de bancos estrangeiros nos mercados domésticos das economias emergentes, tendo seus governos papel ativo neste processo.

O capítulo 9 explica, com riqueza de detalhes e de evidências empíricas, a mudança no padrão de lucratividade e na estrutura operacional do sistema bancário brasileiro após o fim do regime de alta inflação no país, em 1994. São apontados os problemas vividos pelo sistema bancário após o Plano Real (1994), suas causas e consequências, e a exitosa atuação do governo com a implementação dos Programas PROES e PROER e do Fundo Garantidor de Crédito. A adoção destes programas e políticas para o setor bancário impediu a instalação de crise sistêmica bancária no país, permitiu a reestruturação do sistema bancário e estimulou uma onda de F\&A, inclusive com a penetração de bancos estrangeiros no sistema bancário brasileiro.

Neste capítulo o autor apresenta os efeitos esperados da entrada de bancos estrangeiros no mercado doméstico e os resultados alcançados. Ainda, são apontados fatores que explicam a resistência do setor bancário brasileiro às vicissitudes observadas no mercado doméstico após 1994, tais como as crises do México (1994/95), da Ásia (1997), a penetração de bancos estrangeiros, etc. Entre estes fatores destacam-se as características da dívida pública interna do Brasil, que combina liquidez com lucratividade, isto é, nossa dívida interna não impõe aos bancos o clássico trade-off liquidez x lucratividade. 
A seção 9.3 analisa os impactos do processo de consolidação bancária no Brasil sobre o tamanho do setor bancário, market share, grau de concentração, desempenho, etc., e avalia se a consolidação bancária no país seguiu a tendência internacional, evidenciando as peculiaridades do caso brasileiro. Assim como ocorre nas demais seções, toda a análise desenvolvida é cuidadosamente amparada por dados e evidências empíricas. Entre as conclusões estão a redução do número de bancos; a concentração do mercado bancário; presença de elevadas margens (a despeito da entrada de bancos estrangeiros no mercado doméstico); a participação ativa dos bancos tanto domésticos como também estrangeiros na onda de F\&A após 1994.

O capítulo 10 testa empiricamente se houve mudança na eficiência (microeconômica) dos bancos que estiveram envolvidos no processo de F\&A no Brasil, e efetua análise comparativa entre eles. São seis grandes bancos, sendo três controlados por capital privado doméstico e três por capital externo - Bradesco, Itaú, Unibanco, Santander, ABN AMRO e HSBC.

Os poucos estudos existentes sobre a relação entre $F \& A$ e eficiência no mercado bancário brasileiro cobrem apenas o período inicial do processo de $\mathrm{F} \& \mathrm{~A}$, não abrangendo o período posterior a 2003. O capítulo 10 contribui com a literatura ao realizar estudo empírico sobre a relação entre F\&A e eficiência no mercado bancário brasileiro para o período 1998-2008. Adotaram-se dois modelos: um para testar a eficiência dos bancos na sua tradicional atividade de empréstimos (intermediação financeira) e outro para testar a eficiência dos bancos na geração de renda (lucratividade bancária). Como metodologia adotou-se o método não paramétrico de Análise Envoltória de Dados (Data Envelopment Analysis - DEA).

Os resultados obtidos sugerem ganhos de eficiência dos bancos no período de F\&A no mercado brasileiro. Os bancos privados domésticos apresentaram melhor desempenho em termos de eficiência vis-à-vis bancos estrangeiros, principalmente no caso do modelo de intermediação financeira. Os resultados sugerem que a penetração de bancos estrangeiros no país forçou os bancos domésticos a operarem com maior eficiência. Por fim, o autor elabora os argumentos que explicam estes resultados encontrados e constata que, ao contrário do que é sugerido na literatura internacional, no caso brasileiro bancos estrangeiros não são mais eficientes do que bancos domésticos. 
Após vinte anos do início da liberalização financeira no país e dado o cenário atual de crise financeira mundial, um balanço sobre causas e consequências da abertura da conta de capital no Brasil é oportuno e necessário. O livro Financial Liberalization and Economic Performance: Brazil at the Crossroads, de Luiz Fernando de Paula, é leitura obrigatória e, sobretudo, prazerosa, para quem deseja entender os argumentos favoráveis e contrários à liberalização financeira, a experiência brasileira de liberalização financeira, suas causas e consequências, as características do sistema bancário brasileiro e seu processo de $\mathrm{F} \& \mathrm{~A}$, suas semelhanças e diferenças com a indústria bancária mundial, as profundas mudanças observadas no setor bancário do país após a estabilização de preços (Plano Real, 1994) e suas tendências atuais. 